\title{
SARS-CoV-2 in a Tropical Area of Colombia, a Remarkable Conversion of Presymptomatic to Symptomatic People Impacts Public Health
}

\section{Caty Martinez}

Universidad de Cordoba

Hector Serrano

Universidad de Cordoba

Salim Mattar ( $\square$ mattarsalim@hotmail.com )

Universidad de Cordoba, Colombia https://orcid.org/0000-0003-0526-4630

Álvaro A. Faccini-Martínez

universidad de cordoba

Veronica Contreras

Universidad de Cordoba

Ketty Galeano

Universidad de cordoba

\section{Yesica Botero}

Universidad de Cordoba

\section{Yonairo Herrera}

Universidad de Cordoba

\section{Alejandra Garcia}

Universidad de Cordoba

\section{Evelin Garay}

Universidad de Cordoba

\section{Ricardo Rivero}

Universidad de Cordoba

Hector Contreras

Universidad de Cordoba

\section{Yesica Lopez}

Universidad de Cordoba

Camilo Guzman

Universidad de Cordoba

Jorge Miranda

Universidad de Cordoba

German Arrieta 


\section{Research article}

Keywords: Confounding factors epidemiology, presymptomatic disease, preventive measures, preventive medicine and public health, disease transmission, infectious

Posted Date: November 23rd, 2020

DOI: https://doi.org/10.21203/rs.3.rs-111785/v1

License: (c) (i) This work is licensed under a Creative Commons Attribution 4.0 International License. Read Full License 


\section{Abstract}

The ability of SARS-CoV-2 to remain in asymptomatic individuals facilitates its dissemination and makes its control difficult. Objective. To establish a cohort of asymptomatic individuals, change to the symptomatic state, and determine the most frequent clinical manifestations. Methods. Between April 9 and August 9, 2020, molecular diagnosis of SARS-CoV-2 infection was confirmed in 154 asymptomatic people in contact with subjects diagnosed with COVID-19. Nasopharyngeal swabs were performed on these people in different hospitals in Córdoba, the Caribbean area of Colombia. The genes $\mathrm{E}, \mathrm{RdRp}$, and $\mathrm{N}$ were amplified with RT-qPCR. Based on the molecular results and the Cq values, the patients were subsequently followed up through telephone calls to verify their health conditions. Results. Overall, of 154 asymptomatic individuals, 103 (66.9\%) remained asymptomatic, and 51 (33.1\%) changed to symptomatic. The most frequent clinical manifestations in young people were anosmia and arthralgia; in adults, they were cough, ageusia, and odynophagia; in the elderly were epigastralgia, dyspnea, and headache. Mortality was $8 \%$. Conclusions. A proportion of $33 \%$ of presymptomatic individuals was found, of which four of them died. This high rate could indicate a silent transmission, contributing significantly to the increase in the epidemic associated with SARS-CoV-2.

\section{Introduction}

The SARS-CoV-2 infection has put the world's health systems to the test to serve millions of people. However, and despite social restriction and self-care measures, the advance of infections continues. This pandemic's epidemiological problem lies in the virus's ability to remain in asymptomatic people, increasing the rate of transmissibility and preventing timely measures to contain the spread. Early identification and isolation of carriers reduce the risk of virus shedding. For this reason, it is essential to increase the screening of the asymptomatic population; unfortunately, the Colombian Ministry of Health suspended RT-qPCR tests for the detection of SARS-CoV-2 infection in this population (1).

Some reports show that about half of all SARS-CoV-2 transmissions occur before the infected individual develops symptoms (2). However, evidence indicates that between $18 \%$ and $81 \%$ of people infected with SARS-CoV-2 never develop symptoms and, consequently, they cannot be detected by health systems. At present, the distinction between asymptomatic and presymptomatic stages can only be made retrospectively, after the appearance or absence of clinical symptoms (3).

This work aimed to establish a cohort of asymptomatic individuals their evolution to symptomatic ones and determine the most frequent clinical manifestations.

\section{Materials And Methods}

Between April 9 and August 9, 2020, molecular diagnosis of SARS-CoV-2 infection was confirmed in 154 asymptomatic people in contact with subjects diagnosed with COVID-19. Oropharyngeal swabs were performed on these people in different hospitals in the department of Córdoba. The samples were submitted to the Institute for Biological Research of the Tropic of the University of Córdoba. The 
department of Córdoba is located in the North of Colombia, the Caribbean area, and it has a population of $1,800,000$ inhabitants. The laboratory is endorsed by the National Institute of Health (INS) to carry out the molecular tests of RT-qPCR, following the Charite of Berlin protocol, which consists of amplifying the genes $E$, RdRp, and N (4). Based on the molecular results and the Cq values, the patients were subsequently followed up through telephone calls to verify their health conditions. They were asked if they had developed symptoms related to the disease and how long they manifested them. The consent of the patients was obtained, and they have categorized strictly anonymously. The work was endorsed by the ethics committee of the Instituto de Investigación Biológicas del Trópico (IIBT). It was carried out under international ethical standards given by the World Health Organization and the Pan American Health Organization, supported by Helsinki's declaration, national legislation, resolution number 008430 of 1993 of the Ministry of Health of Colombia.

Analysis of data. The data were recorded in an Excel database and analyzed using the statistical package Info-stat $^{\mathrm{TM}}, 2018$. The univariate analysis for the qualitative variables was carried out through the calculation of absolute and relative frequencies. The quantitative variables were calculated with measures of central tendency (median). The bivariate analysis for the qualitative variables was performed using Pearson's chi-square test. Besides, a principal component analysis was performed to relate the observations (age categories) and the variables (symptoms) to interpret the reciprocal relationships between observations and variables.

\section{Results And Discussion}

Overall, considering the epidemiological follow-up of 154 asymptomatic individuals, 103 (66.9\%) remained asymptomatic, and 51 (33.1\%) developed symptoms. The patients who remained asymptomatic were 55 women and 53 men $(n=103)$, and their age distribution was as follows: 17 pediatric patients ( $0-$ 17 years), 20 young people ( $18-26$ years), 53 adults (27-59 years), and 18 elderly ( $>60$ years).

The 51 patients who developed symptoms of the disease (presymptomatic) were 22 women (43\%) and 29 men (57\%). No statistically significant differences were found when comparing men and women ( $p=$ 0.327). The most frequent clinical manifestations in men were dyspnea, cough, fever, epigastralgia, and headache, while in women, they were adynamia, anosmia, arthralgia, ageusia, odynophagia, diarrhea, myalgia, and chest pain (Fig. 1).

The average time of conversion from the asymptomatic to symptomatic status was between 1-3 days (43.1\%), 4-7 days (19.6\%), 8-10 days (3.9\%), and between $11-15$ days (9.9\%); $23.5 \%$ did not remember the time concerning the onset of symptoms. The median $\mathrm{Cq}$ of asymptomatic patients was 37.35 , and that of symptomatic patients was 35.24 .

The main symptoms for all age groups were headache, fever, and anosmia (Table 1). When performing the principal component analysis for each of these groups, it was determined that in the elderly, the main manifestations were epigastric pain, dyspnea, and headache. In adults, the most common symptoms were cough, ageusia, and odynophagia, while in young people, they were anosmia and arthralgia (Fig. 2). 
Table 1

Distribution of symptoms according the age.

\begin{tabular}{|lllll|}
\hline Symptoms & Young $\%$ & Adult ${ }^{2} \%$ & \multicolumn{1}{l}{ Elderly $\%$} & Total \% \\
\hline Headache & $(4 / 10) 0,08$ & $(10 / 28) 0,20$ & $(7 / 13) 0,14$ & $(21 / 51) 0,41$ \\
\hline Fever & $(2 / 10) 0,04$ & $(10 / 28) 0,20$ & $(8 / 13) 0,16$ & $(20 / 51) 0,39$ \\
\hline Anosmia & $(3 / 10) 0,06$ & $(8 / 28) 0,16$ & $(2 / 13) 0,04$ & $(13 / 51) 0,25$ \\
\hline Cough & $(2 / 10) 0,04$ & $(10 / 28) 0,20$ & 0 & $(12 / 51) 0,24$ \\
\hline Adinamia & $(1 / 10) 0,02$ & $(9 / 28) 0,18$ & $(1 / 13) 0,02$ & $(11 / 51) 0,22$ \\
\hline Dyspnoea & $(2 / 10) 0,02$ & $(4 / 28) 0,08$ & $(5 / 13) 0,10$ & $(10 / 51) 0,20$ \\
\hline Diarhrea & $(2 / 10) 0,04$ & $(6 / 28) 0,12$ & $(2 / 13) 0,04$ & $(10 / 51) 0,20$ \\
\hline Ageusia & $(2 / 10) 0,04$ & $(7 / 28) 0,14$ & $(1 / 13) 0,02$ & $(10 / 51) 0,20$ \\
\hline Odynophagia & $(2 / 10) 0,04$ & $(7 / 28) 0,14$ & 0 & $(9 / 51) 0,18$ \\
\hline Myalgia & $(1 / 10) 0,02$ & $(5 / 28) 0,10$ & $(2 / 13) 0,04$ & $(8 / 51) 0,16$ \\
\hline Arthralgia & $(2 / 10) 0,04$ & $(6 / 28) 0,12$ & 0 & $(8 / 51) 0,16$ \\
\hline Pain of thorax & 0 & $(3 / 28) 0,06$ & $(2 / 13) 0,04$ & $(5 / 51) 0,10$ \\
\hline Epigastralgia & 0 & 0 & $(1 / 13) 0,02$ & $(1 / 51) 0,02$ \\
\hline Young ${ }^{1}$ 18-26 (included one child of 12 years old); Adult 2 27-59 years; Elderly ${ }^{3}>60$ years. \\
\hline
\end{tabular}

Four elderly patients who became symptomatic died, three men with comorbidities (heart disease, cancer, and kidney disease) and one woman without comorbidities. This last patient passed away during medical care at her home. It is important to note that deceased individuals' Cq values (median 29.93) were lower than that of asymptomatic and symptomatic individuals (median 37.35 and 35.24 , respectively).

This study is the first to be carried out in Colombia on the change in status from presymptomatic to symptomatic. In this study, it was found that $33.1 \%$ of the patients were in a presymptomatic state, and four $(8 \%)$ of them died. This significant proportion could mean an eventual silent transmission, contributing to increased cases in the epidemic associated with SARS-CoV-2 (5).

There are models to estimate the transmission rate of asymptomatic infections from unknown sources, and they are estimated at 55\%; in documented cases, it is estimated to be around $79 \%$ (6). Our study cannot infer these proportions; however, it highlights that $33.1 \%$ could have had an actual weight in the increase in cases at the time. Other reports had described that $31 \%(5 / 16)$ of the transmissions occurred before the symptoms appeared. In our case, this critical epidemiological data is unknown. However, in a study carried out in China with a smaller number of patients than our study, they found 19 asymptomatic 
cases and five presymptomatic cases and found that only $4.2 \%(1 / 24)$ of the cases resulted in secondary transmission (7). According to the authors (7), the low asymptomatic/presymptomatic transmission rate could have been due to people's isolation during the outbreak. A similar situation happened in Colombia, but our 33.1\% proportion was higher than them. However, other studies (7) of indirect transmission have shown that symptomatic cases transmitted SARS-CoV-2 to $16.2 \%$ (34/210) of domestic contacts; but there was no asymptomatic or presymptomatic spread in 15 of the domestic contacts. Finding different from ours found $33.1 \%$.

On the other hand, our findings demonstrated that the most common clinical manifestations in individuals who evolved to symptoms were headache, fever, and anosmia. These findings agree with Fu et al. (8), who found that the main clinical manifestations of COVID-19 are fever, headache, cough, and dyspnea.

According to age, it was observed that the most common symptoms were anosmia and arthralgia in young people. Young individuals do not seem to have significantly lower respiratory tract involvement. However, SARS-CoV-2 infection significantly affects the upper respiratory tract, mainly causing neurological manifestations such as olfactory dysfunction, lasting up to 28 days (9). Anosmia can be a pathognomonic clinical manifestation that could be used by healthcare personnel to differentiate SARSCoV-2 infection from other respiratory viruses such as influenza (10). Another study in Korea also evidenced anosmia as a frequent symptom in 3,191 young people with COVID-19 and was characteristic in mild forms of the disease (11).

In adults, the most important clinical manifestations were cough, ageusia, and odynophagia, consistent with what was published (12). It is striking to show that another neurological manifestation such as ageusia is one of the most frequent clinical symptoms during SARS-CoV-2 infection, which could be associated with greater involvement of the virus on the glossopharyngeal, facial, and vagus nerves in this age group (13). Therefore, ageusia could serve as a pathognomonic symptom to make a diagnosis in the adult population.

In the elderly, the clinical manifestations were epigastric pain, dyspnea, and headache. Dyspnea was in the present work a specific manifestation of older adults infected by SARS-CoV2 (14). Dyspnea should be considered a clinical symptom with a poor prognosis, mainly in patients with comorbidities such as hypertension, cardiovascular disease, COPD, and kidney disease $(15,16)$.

Regarding the clinical manifestations related to gender, in this study, it was established that in men, a more significant compromise of the lower respiratory tract (cough, dyspnea) was significant would be related to greater severity and a worse clinical prognosis for COVID-19 (15). While in women, mild nonspecific clinical symptoms of the upper respiratory tract were found, which could be related to a less severe infection. These findings are in agreement with Jin et al. (17), who showed that the clinical manifestations in men were more severe than in women and a healthier lifestyle could explain this in women and by biological and immunological differences such as high expression of the ACE2 receptors for SARS-CoV-2 in men (18). 
Of the 51 individuals who became symptomatic, $4(8 \%)$ of them died. Advanced age could be related to mortality (mean 69, range 62-75). Besides, they had comorbidities such as cancer, heart disease, and kidney disease. It is also interesting to mention that they had high viral loads with Cqs between 17.9536.62. In the future, asymptomatic patients with high viral loads should be closely monitored by healthcare personnel.

The present study has some limitations; first, we do not know how long asymptomatic individuals were infected while in contact with other individuals before diagnosis. The study also did not include data on the observed incubation period, and our data could be limited mainly to the Colombian Caribbean population.

In conclusion, the present study demonstrates the importance of performing diagnostic tests among the contacts of individuals positive for SARS-CoV-2 since they could behave as direct disseminators of the disease. The detection of asymptomatic and presymptomatic individuals allows epidemiological screening and control of the proliferation of cases. Because of the high proportion of presymptomatic patients found in the present study and without the guarantee of a vaccine for Latin America in the next seven months, we believe that in the absence of symptoms, we have as our only the following weapons: social distancing, the use of face masks, and adequate hands hygiene. The result indicates that the country's Public Health authorities must return to intensive tracking of apparently healthy contacts or people.

\section{Declarations}

\section{Ethics approval and consent to participate and Consent for publication}

The research committee of the Instituto de Investigaciones Biológicas del Trópico of the University of Cordoba approved the ethics protocol. Patients were registered using an anonymous numeric code. The study incorporated procedures, management, and conservation of samples, and technical-administrative procedures for health research required by resolution 8430 of the Ministry of Health of Colombia, in 1993 and Declaration of Helsinki for ethical and medical research in human subjects. The study was considered as minimal risk.

\section{Competing interests}

The authors declare no conflict of interest applicable to this research.

\section{Funding}

The study was supported by Ministerio de Ciencia Tecnología e Innovación, Colombia (MINCIENCIAS). Research project: "Fortalecimiento de capacidades instaladas de ciencia y tecnología de la Universidad de Córdoba para atender problemáticas asociadas con agentes biológicos de alto riesgo para la salud humana en el departamento de Córdoba" (BPIN Code: 20200000100090). 


\section{Authors' contributions}

CM, HS, SM, ÁAFM design the study, VC, KG, YB, YH, AG, EG, RR, HC, YL, CG, JM, GA carried out the RTqPCR tests and reviewed the article.

\section{Acknowledgements}

The study was supported by Ministerio de Ciencia Tecnología e Innovación, Colombia (MINCIENCIAS). Research project: "Fortalecimiento de capacidades instaladas de ciencia y tecnología de la Universidad de Córdoba para atender problemáticas asociadas con agentes biológicos de alto riesgo para la salud humana en el departamento de Córdoba" (BPIN Code: 20200000100090).

\section{References}

1. Ministerio de Salud y Proteccion Social. Lineamientos para el uso de pruebas moleculares RT-PCR, pruebas de antígeno y pruebas serológicas para SARS-CoV-2 (COVID-19) en Colombia [Internet]. 2020. Available from:

https://www.minsalud.gov.co/Ministerio/Institucional/Procesos\%20y\%20procedimientos/GIPS21.pdf

2. Ferretti L, Wymant $C$, Kendall M, Zhao L, Nurtay A, Abeler-Dörner L, et al. Quantifying SARS-CoV-2 transmission suggests epidemic control with digital contact tracing. Science. 2020 08;368(6491).

3. Nikolai LA, Meyer CG, Kremsner PG, Velavan TP. Asymptomatic SARS Coronavirus 2 infection: Invisible yet invincible. Int J Infect Dis IJID Off Publ Int Soc Infect Dis. 2020 Sep 3;100:112-6.

4. Corman V, Bleicker T, Brünink S, Drosten C. Diagnostic detection of 2019-nCoV by real-time RT-PCR [Internet]. 2020. Available from: https://www.who.int/docs/default-source/coronaviruse/protocol-v21.pdf

5. Zhang Y, Muscatello D, Tian Y, Chen Y, Li S, Duan W, et al. Role of presymptomatic transmission of COVID-19: evidence from Beijing, China. J Epidemiol Community Health. 2020;

6. Eikenberry SE, Mancuso M, Iboi E, Phan T, Eikenberry K, Kuang Y, et al. To mask or not to mask: Modeling the potential for face mask use by the general public to curtail the COVID-19 pandemic. Infect Dis Model. 2020;5:293-308.

7. Slifka MK, Gao L. Is presymptomatic spread a major contributor to COVID-19 transmission? Nat Med. 2020 Aug 17;

8. Fu L, Wang B, Yuan T, Chen X, Ao Y, Fitzpatrick T, et al. Clinical characteristics of coronavirus disease 2019 (COVID-19) in China: A systematic review and meta-analysis. J Infect. 2020;80(6):656-65.

9. Klopfenstein T, Zahra H, Kadiane-Oussou NJ, Lepiller Q, Royer P-Y, Toko L, et al. New loss of smell and taste: Uncommon symptoms in COVID-19 patients in Nord Franche-Comte cluster, France. Int J Infect Dis IJID Off Publ Int Soc Infect Dis. 2020;100:117-22.

10. Meng X, Deng Y, Dai Z, Meng Z. COVID-19 and anosmia: A review based on up-to-date knowledge. Am J Otolaryngol. 2020;41(5):102581. 
11. Lee Y, Min P, Lee S, Kim SW. Prevalence and Duration of Acute Loss of Smell or Taste in COVID-19 Patients. J Korean Med Sci. 2020;35(18):e174.

12. Daher VB, Soares Oliveira DS, Daher Júnior MF, Júnior de Melo Fernandes E, Bomtempo de Castro JV, Moya MI, et al. Anosmia: A marker of infection by the new corona virus. Respir Med Case Rep. 2020;31:101129.

13. Patel A, Charani E, Ariyanayagam D, Abdulaal A, Denny SJ, Mughal N, et al. New-onset anosmia and ageusia in adult patients diagnosed with SARS-CoV-2 infection. Clin Microbiol Infect Off Publ Eur Soc Clin Microbiol Infect Dis. 2020 Jun 2;

14. Niu S, Tian S, Lou J, Kang X, Zhang L, Lian H, et al. Clinical characteristics of older patients infected with COVID-19: A descriptive study. Arch Gerontol Geriatr. 2020 Aug;89:104058.

15. Shi L, Wang Y, Wang Y, Duan G, Yang H. Dyspnea rather than fever is a risk factor for predicting mortality in patients with COVID-19. J Infect. 2020;81(4):647-79.

16. Guan W-J, Liang W-H, Zhao Y, Liang H-R, Chen Z-S, Li Y-M, et al. Comorbidity and its impact on 1590 patients with COVID-19 in China: a nationwide analysis. Eur Respir J. 2020;55(5).

17. Jin J-M, Bai P, He W, Wu F, Liu X-F, Han D-M, et al. Gender Differences in Patients With COVID-19: Focus on Severity and Mortality. Front Public Health. 2020;8:152.

18. Bwire GM. Coronavirus: Why Men are More Vulnerable to Covid-19 Than Women? SN Compr Clin Med. 2020 Jun 4;1-3.

\section{Figures}




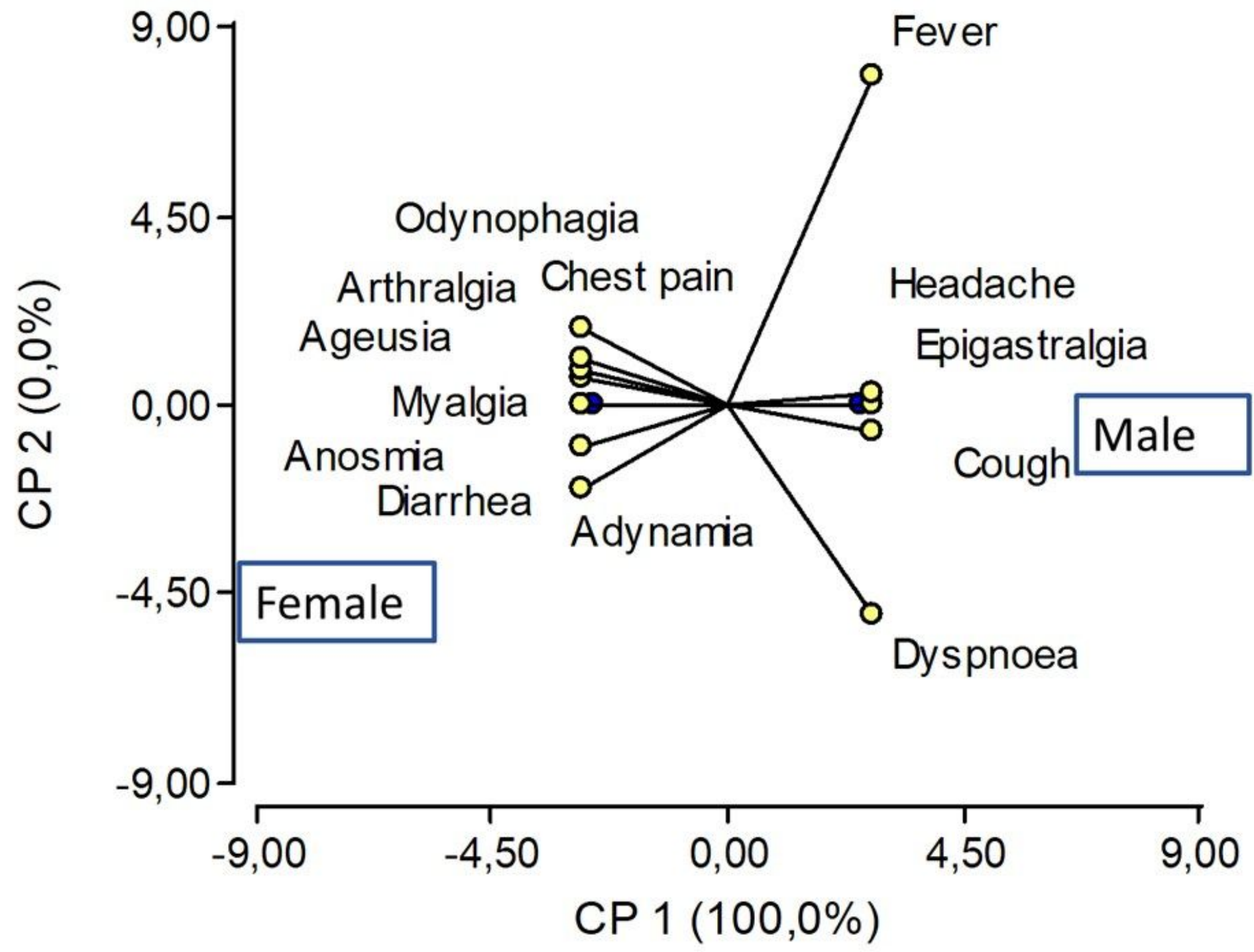

Figure 1

Principal component analysis of gender and COVID-19 symptoms. The principal component, CP1, explains $100 \%$ of the variability of the data. The clinical symptoms associated with men are dyspnea, cough, epigastric pain; in women, they are anosmia, myalgia, and diarrhea. 


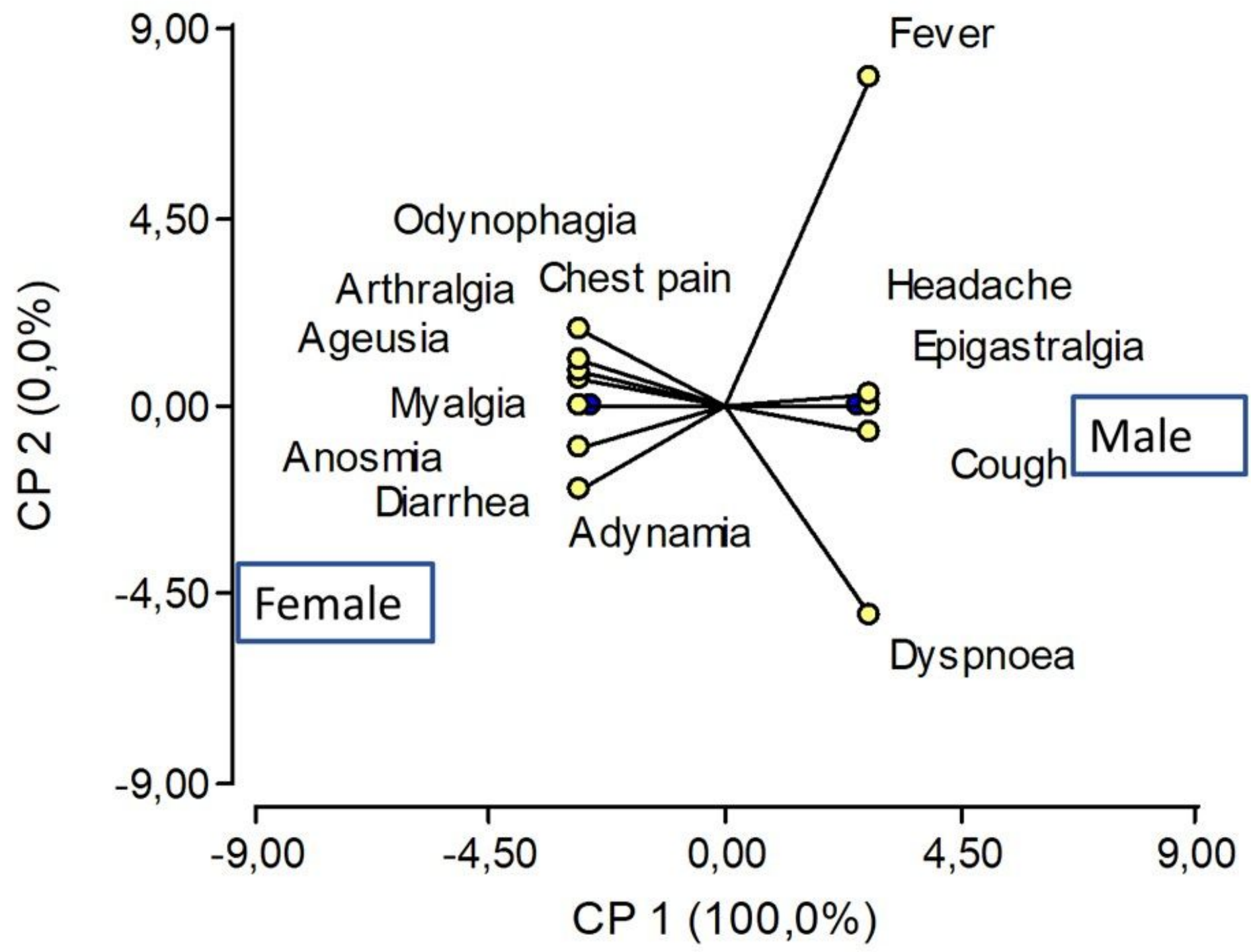

Figure 1

Principal component analysis of gender and COVID-19 symptoms. The principal component, CP1, explains $100 \%$ of the variability of the data. The clinical symptoms associated with men are dyspnea, cough, epigastric pain; in women, they are anosmia, myalgia, and diarrhea. 


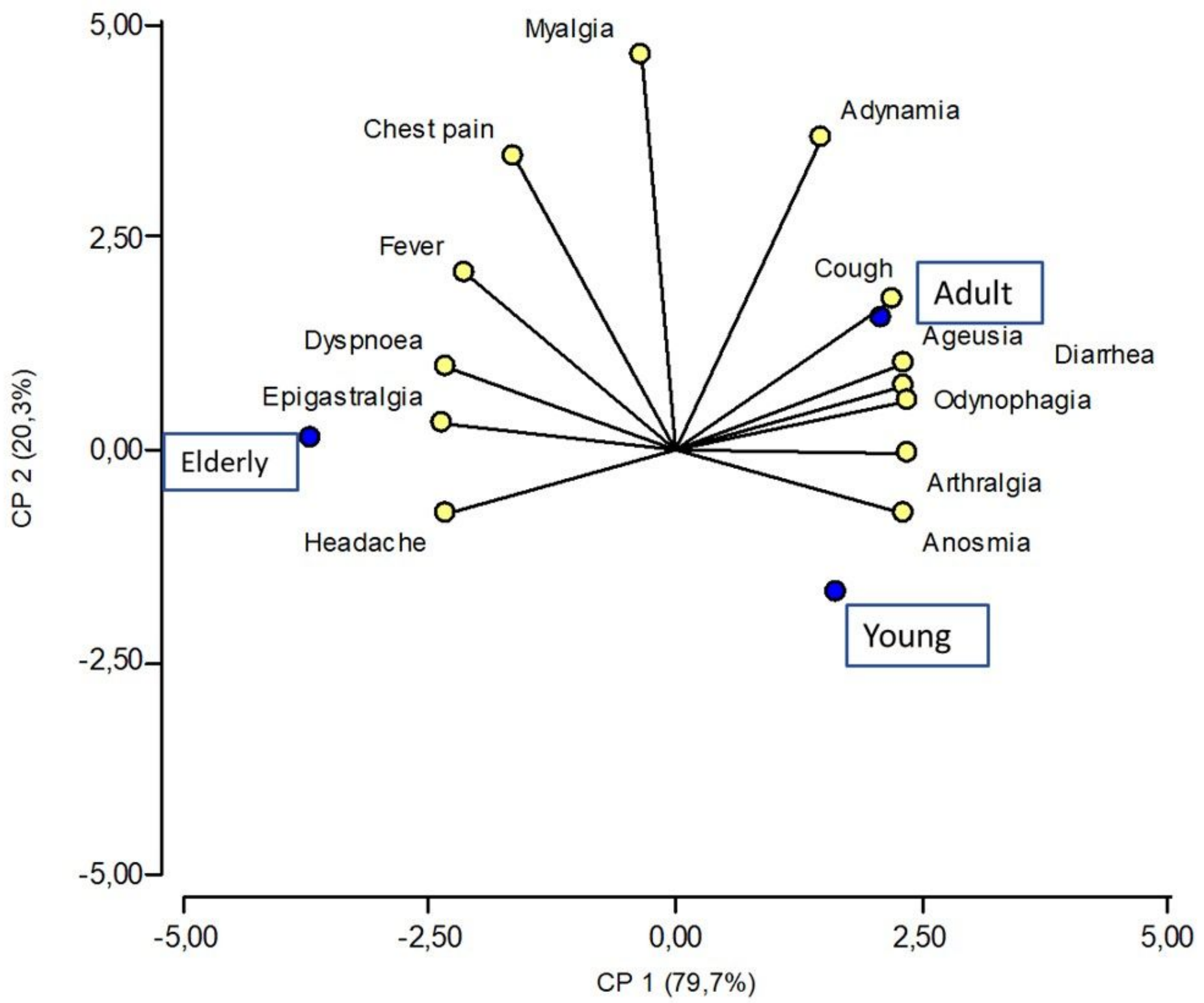

Figure 2

Principal component analysis of age categories and COVID-19 symptoms. The principal component, CP1, explains $79.7 \%$ of the variability of the data. The principal component, CP2, explains $20.3 \%$ of the variability of the data. $\mathrm{CP} 1$ and $\mathrm{CP} 2$ relate the main clinical manifestations for young people (anosmia and arthralgia); in adults (cough, diarrhea, and odynophagia); in elderly patients (epigastralgia, dyspnea, and headache). 


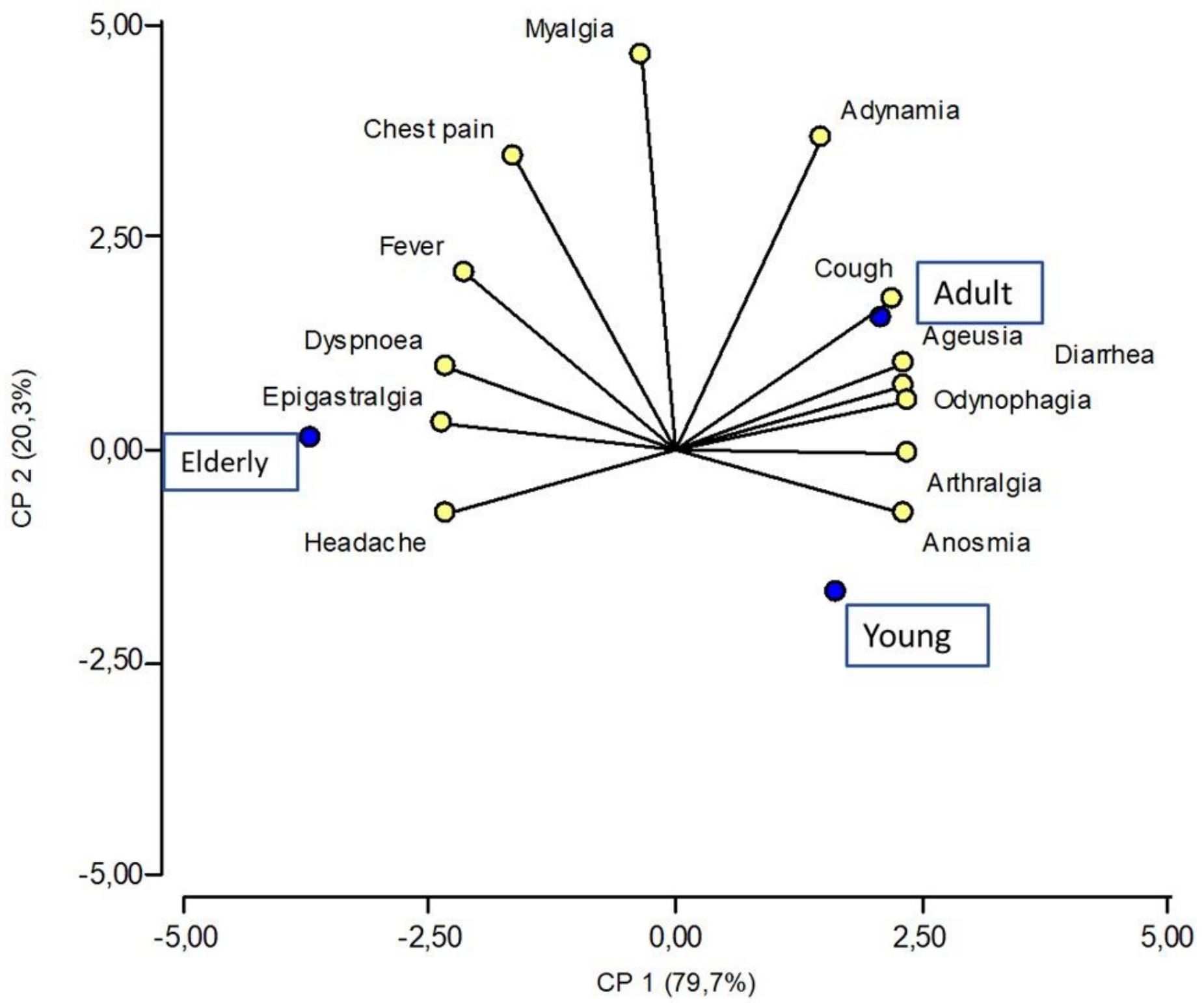

Figure 2

Principal component analysis of age categories and COVID-19 symptoms. The principal component, CP1, explains $79.7 \%$ of the variability of the data. The principal component, CP2, explains $20.3 \%$ of the variability of the data. $\mathrm{CP} 1$ and $\mathrm{CP} 2$ relate the main clinical manifestations for young people (anosmia and arthralgia); in adults (cough, diarrhea, and odynophagia); in elderly patients (epigastralgia, dyspnea, and headache). 